\title{
Itinerário Terapêutico Percorrido por Mães de Crianças com Transtorno Autístico
}

\author{
Therapeutic Itinerary Done by Mothers of Children with Autistic Disorder ${ }^{l}$
}

\author{
Maria Angela Favero-Nunes \& Manoel Antônio dos Santos* \\ Universidade de São Paulo
}

\begin{abstract}
Resumo
O objetivo do presente estudo é examinar o itinerário percorrido por mães de crianças com transtorno autístico na busca do diagnóstico e tratamento, relacionando-o com a convivência com o filho acometido. As participantes foram 20 mães, vinculadas a duas instituições de atendimento. Realizou-se uma entrevista com roteiro semi-estruturado, complementada por questionário sociodemográfico. Foram encontrados quatro núcleos temáticos: trajetória materna para conhecer o problema da criança, marcada por um movimento de peregrinação por serviços de saúde; modos de lidar com as dificuldades da criança; sobrecarga emocional materna; desamparo quanto ao futuro da criança. Conhecer o itinerário terapêutico contribui para o planejamento de programas e serviços especializados.
\end{abstract}

Palavras-chave: Transtorno Autístico; Mães; Saúde Mental.

\begin{abstract}
This study aims at examining the itinerary done by mothers of children with autistic disorder in the search for diagnosis and treatment and their relationship with their child. The participants were twenty mothers, whose child was cared in two public institutions in different cities in the State of São Paulo. A semi-structured interview has been applied as well as a socio-demographic questionnaire. Four thematic nuclei had been found: (a) the family's pilgrimage to health services in order to diagnose their child's condition; (b) the ways to deal with the child's difficulties; (c) the mother's emotional burden; and (d) the parents' helplessness in what concerns future perspectives for the child. Acknowledging such itinerary contributes to improve the planning regarding more specialized programs and services.

Keywords: Autistic Disorder; Mothers; Mental Health.
\end{abstract}

O reconhecimento de uma deficiência física e/ou mental em um membro da família pode desencadear sobrecarga emocional (Fávero, 2005; Kovács, 1997). Os pais são confrontados com uma situação nova, que exige reajustamento e desperta fantasias específicas. Segundo Teperman (1999, p. 153) "o desejo fantasiado da gestação precisa de uma adequação àquele que nasce e que tem características próprias". A condição especial da criança requer que os pais encarem o luto pelo filho idealizado e providenciem formas de ajustamento a esta realidade.

Estudos na área do autismo infantil têm sido permeados pela diversidade, principalmente naquilo que diz respei-

\footnotetext{
* Endereço para correspondência: Universidade de São Paulo, Faculdade de Filosofia, Ciências e Letras de Ribeirão Preto, Departamento de Psicologia e Educação, Av. Bandeirantes, 3900, Bloco E, Bairro Monte Alegre, Ribeirão Preto, SP, Brasil, CEP 14040-901. Tel.: 163602 3645; Fax 163602 4835. E-mail: masantos@ ffclrp.usp.br

${ }^{1}$ Este estudo é derivado da dissertação de mestrado da primeira autora, intitulada "Trajetoria e sobrecarga emocional da família de crianças autistas: relatos maternos", sob orientação do segundo autor, financiado pela FAPESP, processo ${ }^{\circ} 02 / 11665-9$.
}

to à etiologia. Bosa e Callias (2000) examinaram as principais teorias psicológicas que abordam esse tema e que divergem na atribuição de causalidade ao quadro (afetiva, cognitiva, biológica), debatendo se o transtorno é decorrente de deficits inatos ou ambientais. As autoras sintetizaram as principais teorias da área, assim denominadas: teorias psicanalíticas, afetivas, neuropsicológicas e de processamento de informação, teoria da mente, teoria da função executiva e da coerência central. Concluíram que, a partir do estudo do autismo, expandiram-se consideravelmente as pesquisas sobre os processos constitucionais e ambientais implicados no desenvolvimento humano (Bosa \& Callias, 2000). Na visão de Cavalcanti e Rocha (2002), o interesse despertado pelo desenvolvimento de pesquisas e teorias sobre o autismo deve-se, especialmente, a sua "incidência nos primórdios da constituição do psiquismo humano” (p. 29).

Usualmente, o DSM-IV-TR (American Psychiatric Association, 2002) utiliza a classificação de Transtornos Globais do Desenvolvimento (TGDs), que abrange: Transtorno Autista, Transtorno de Rett, Transtorno Desintegrativo da Infância, Transtorno de Asperger e Transtorno Global do Desenvolvimento sem outra Especificação. A CID-10 indi- 
ca que indivíduos autistas se caracterizam por "alterações qualitativas das interações sociais recíprocas e modalidades de comunicação e por um repertório de interesses e atividades restrito, estereotipado e repetitivo" (Organização Mundial da Saúde, 2000, p. 367).

Chamak (2008) conduziu uma análise dos movimentos sociais empreendidos por associações francesas e organizações internacionais, relacionados a indivíduos com o transtorno autístico. A autora concluiu que a adoção de uma classificação internacional, com um critério amplo de diagnóstico do autismo na categoria dos TGDs, tem permitido aos pais dar um nome a algo inexplicável, bem como contribui para o encontro de famílias e para o fornecimento de ajuda no que se refere a serviços sociais e escolas especiais (Chamak, 2008).

Atualmente, encontra-se também a denominação transtorno abrangente do desenvolvimento (Zukauskas \& Assumpção, 2002), considerando-se que a psicopatologia pode variar amplamente com relação à gravidade, mantendo em comum certos sintomas característicos, tais como isolamento social, ausência de contato visual, pobreza de expressão verbal e inexistência de empatia (Ramachardan \& Oberman, 2006). Segundo Lampreia (2003), o transtorno autístico abrange um espectro heterogêneo de quadros comportamentais. Aproximadamente dois terços dessas crianças permanecem incapazes de viver independentemente e somente um terço pode atingir algum grau de independência pessoal quando adulta (Klin, 2006).

Atualmente, pesquisas neuropsicológicas têm comprovado a presença de anormalidades cerebrais em indivíduos autistas (Zilbovicius, Meresse, \& Boddaert, 2006). Entretanto, Alvarez (1994) compreende que, embora muitas vezes o autismo possa começar com alguma disfunção neurológica, o subseqüente déficit psicológico deve levar em consideração o estágio de desenvolvimento das relações objetais e a capacidade da criança para comunicação emocional.

Partindo de uma abordagem multidisciplinar "atravessada pela Psicanálise” (Lerner, 2008, p. 10), realiza-se, atualmente, no contexto brasileiro, a Pesquisa Multicêntrica de Indicadores Clínicos de Risco para o Desenvolvimento Infantil (IRDI), subsidiada pela Fundação de Amparo à Pesquisa do Estado de São Paulo (FAPESP), pelo Conselho Nacional de Desenvolvimento Científico e Tecnológico (CNPq) e pelo Ministério da Saúde. Esse estudo é produto da articulação do conhecimento oriundo de diferentes áreas, como a psicanálise, pediatria, nutrição, fonoaudiologia e psiquiatria na tentativa de localizar previamente transtornos futuros (Kupfer, Rocha, Cavalcanti, Escobar, \& Fingerman, 2008), conduzido em diversos centros de pesquisa do país. A investigação busca oferecer subsídios para a elaboração de um protocolo que possa ser utilizado por profissionais das áreas da saúde e educação, que atendem crianças de zero a 18 meses de vida. Os indicadores para o desenvolvimento baseiam-se em quatro eixos: a suposição de sujeito, o estabelecimento da demanda, a alternância presença-ausência e a função paterna (Kupfer et al., 2008).

Para alguns pesquisadores expoentes da área, tanto organicistas quanto psicodinamicistas, a tendência atual é aceitar uma causação múltipla para o autismo, ainda que os organicistas restrinjam essa multiplicidade ao aspecto puramente médico (Alvarez, 1994). Para Alvarez (2007), podemos geralmente encontrar em cada pessoa autista uma parte intacta, não-autista, de sua personalidade, emaranhada com seu autismo. Assim, adotando-se uma postura psicodinâmica, o transtorno autístico pode ser compreendido como uma condição da personalidade resultante de multicausalidades e não de uma origem psicogênica apenas.

A literatura aponta que os cuidadores formais dessas crianças vivenciam uma sobrecarga emocional elevada, o que colabora para o aumento da vulnerabilidade e um risco maior de acometimento por doenças (Fávero, 2005; Fávero \& Santos, 2005; Fisman \& Wolf, 1991; Henderson \& Vandenberg, 1992; Sanders \& Morgan, 1997; Sprovieri \& Assumpção, 2001). Schmidt e Bosa (2003), em uma revisão crítica da literatura sobre autismo na família, salientaram que as pesquisas atuais enfatizam os efeitos que a criança com TGD exerce sobre os pais, ao contrário do que ocorria anteriormente, quando as pesquisas tratavam de investigar os efeitos dos pais sobre a criança com o transtorno.

É conhecido que o fato de os pais se defrontarem com as chamadas "estereotipias" da criança, o isolamento, a ausência do brincar, culmina, muitas vezes, com o próprio afastamento familiar em relação à vida social. As preocupações com a gravidade dos sintomas e com a agressividade do filho tornam o estresse da família da criança com autismo maior quando comparado com famílias de crianças portadoras de outras enfermidades, tais como a síndrome de Down (Bolton et al., 1994; Bolton, Pickles, Murphy, \& Rutter, 1998; Mickelson, Wroble, \& Hielgeson, 1999; Piven \& Palmer, 1999; Sprovieri \& Assumpção, 2001).

No estudo de Moes, Koegel, Schreibman e Loos (1992), mães de crianças autistas mostraram significativamente mais estresse do que os pais, sugerindo que o estresse pode estar relacionado às diferentes responsabilidades com a criança designadas para cada cuidador. Nesse estudo, os pais estavam ativamente comprometidos com a profissão fora de casa e todas as mães identificaram-se como o cuidador primário.

Estudos sugerem estratégias de enfrentamento efetivas para adaptação dos pais à criança com transtorno autista ou com síndrome de Down, mas poucos examinam as percepções dos pais quanto às suas próprias necessidades (Siklos \& Kerns, 2006). El-Ghoroury e Romanczyk (1999) sugerem que os pais poderiam compensar o nível de inabilidade de suas crianças pela iniciação em jogos de interação para que, então, as crianças comecem por iniciativa própria. 
São escassos na literatura científica, especialmente no âmbito nacional, estudos com propostas de intervenção terapêutica que busquem, por meio da prática clínica, auxiliar preventivamente a família frente às dificuldades a serem enfrentadas. Observa-se que a produção bibliográfica acerca das avaliações com o indivíduo autista e a família (Hare, Pratt, Burton, Bromley, \& Emerson, 2004; Vitiello et al., 2005; Wallace, Leask, \& Trevena, 2006; E. Williams, 2003; Young, Brewer, \& Pattison, 2003) é numerosa quando comparada com a carência de publicações sobre modelos de intervenção com esses indivíduos (Carr, 2003; Ducharme \& Drain, 2004; Francis, 2005; Smith \& Dillenbeck, 2006). Essa carência é ainda mais notável com relação a intervenções terapêuticas com o casal parental (K. R. Williams \& Wishart, 2003). Todavia, Cloutier, Manion, Walker e Johnson (2002) chamam a atenção para o risco de estresse conjugal em casais com crianças cronicamente enfermas.

Outros estudos apresentam modelos de intervenção provocadores de mudanças significativas no estresse vivenciado pelos cuidadores quando inseridos em atendimentos psicológicos (Morales, Martinez, \& Váldes, 1995; Prado, 1999). Para Lino Silva (1998, p. 61), o processo de atendimento psicológico destas crianças pode ser iniciado com tentativas de encontrar uma linguagem comum com a criança, "uma forma de comunicação de modo a que se possam partilhar experiências".

Várias abordagens reconhecem a necessidade de um trabalho não só com a criança autista, mas também com os membros da família. Kupfer (1997, p. 88) relata que o trabalho institucional de atendimento grupal a pais tem se revelado muito significativo e "para muitos pais, o que se verifica é um abandono da posição de culpa" e a adoção de uma posição de responsabilidade.

No cenário nacional, ainda são escassos os estudos que focalizam os cuidadores da criança com transtorno autístico e o processo de busca do tratamento para a criança. A esse processo de escolha, avaliação e adesão a determinadas formas de tratamento, realizadas por indivíduos ou grupos sociais, denominamos itinerário terapêutico (Reinaldo, 2003).

Reinaldo (2003) analisou o itinerário de usuários do serviço de saúde mental por meio da história de vida, no contexto da enfermagem. Gerhardt (2006) investigou o itinerário terapêutico de uma população em situação de pobreza e verificou que, além dos limites das condições materiais, as estratégias de vida foram construídas de acordo com as capacidades, histórias de vida e experiências individuais. Esses estudos demonstram a importância de se investigar a trajetória percorrida por indivíduos na busca de cuidados em saúde.

Mediante a conceitualização psicodinâmica do transtorno autístico e reconhecendo-se a gravidade da sintomatologia da criança, a heterogeneidade do quadro e a complexidade da situação familiar, conduziu-se um estudo descritivo cujo objetivo foi identificar o itinerário terapêutico percorrido por mães de crianças com o transtorno autístico na busca do diagnóstico e tratamento, relacionando-o com a convivência com o filho acometido.

\section{Método}

O delineamento escolhido foi um estudo descritivo de corte transversal, cujos participantes foram mães de crianças que apresentavam traços de comportamentos autísticos. Para a definição das variáveis investigadas, partiu-se do conhecimento proporcionado pela literatura em relação àquelas informações consideradas relevantes para o alcance dos objetivos propostos.

\section{Participantes}

Foram incluídas no estudo 20 participantes, vinculadas a duas instituições especializadas de atendimento a crianças de dois municípios do interior paulista, de perfil sociodemográfico e desenvolvimento econômico semelhantes. Com base nos critérios de inclusão, levantou-se o número de mães elegíveis em cada instituição. Incluíram-se mães com um filho (sexo masculino) em idade infantil (até 12 anos, na época do contato inicial da pesquisadora com a instituição, quando foi realizado o levantamento de casos elegíveis), diagnosticado com transtorno autístico ou transtorno de desenvolvimento acompanhado de características autistas, que aceitaram ser voluntárias e assinaram o Termo de Consentimento Livre e Esclarecido. Foram excluídas as mães que se afastaram desse perfil ou que se recusaram a colaborar. A coleta de dados ocorreu ao longo de dois anos.

A escolha por mães de crianças do sexo masculino ocorreu mediante a verificação na literatura da predominância masculina de aproximadamente três a quatro meninos para cada menina (Talbott, Hales, \& Yudofsky, 1992). Esse critério permitiu maior homogeneização dos dados.

Não foi estabelecido como critério de inclusão a condição de ser mãe biológica da criança, uma vez que o objetivo principal era investigar a sobrecarga emocional mediante o relato materno. Sendo assim, a pesquisadora deparou-se com dois casos de adoção, incluídos na pesquisa.

\section{Contexto do Estudo}

A instituição A é uma entidade educacional, terapêutica e clínica, de utilidade pública, sem fins lucrativos, que oferece programas educacionais de adaptação e integração social. Atende 50 alunos (39 meninos e 11 meninas) divididos em duas turmas (períodos da manhã e tarde). Na condição de referência em diagnóstico, recebe crianças e adolescentes encaminhados por profissionais da área de saúde e hospitalar. Desenvolve atividades de: avaliação, diagnóstico clínico e controle de medicação, avaliação psicopedagógica, atendimento educacional, terapêutico e clínico para crianças e adolescentes com transtorno autístico, além de orientação 
às famílias. $\mathrm{O}$ eixo do tratamento é o desenvolvimento de habilidades sociais, funcionais e de linguagem.

A segunda instituição (B) é uma escola municipal voltada à educação especial, abrangendo os seguimentos da escola, clínica, pesquisa e prevenção. Integra a rede pública de ensino do município e atende 40 crianças e adolescentes (20 no período da manhã e 20 à tarde), sendo 28 meninos e 12 meninas. A proposta de trabalho segue orientação psicanalítica e construtivista, que fundamenta o trabalho pedagógico e o atendimento clínico multidisciplinar, visando promover a integração social. A escola oferece atendimento multidisciplinar para triagem diagnóstica e atendimento clínico individual e grupal a crianças e adolescentes com TID, além de atendimento familiar.

\section{Instrumento}

Foi delineado especialmente para este estudo um instrumento composto de duas partes:

Questionário de Características Sociodemográficas. Incluía questões relacionadas à idade da mãe e da criança, estado civil, escolaridade da mãe, renda familiar, trabalho da mãe, número de filhos e religião. Também foram levantados dados relativos ao diagnóstico, escolaridade e tratamento da criança.

Roteiro de Entrevista Semi-Estruturada. Teve por finalidade investigar, por meio de um roteiro norteador, a história da relação mãe-filho a partir da concepção, gravidez e nascimento da criança com transtorno autístico, o itinerário traçado na busca do diagnóstico, as reações diante do processo de acometimento da criança, as principais dificuldades enfrentadas no período de definição do diagnóstico e no convívio diário com a criança, a maneira como a mãe percebe-se envolvida na relação com seu filho, os reflexos na dinâmica familiar e os projetos de futuro. No caso das mães de crianças adotadas, as questões foram modificadas nos aspectos que se referiam à gestação da criança, solicitando se elas tinham alguma informação sobre esse período, buscando também conhecer quais eram as expectativas diante da inclusão de um novo membro na família.

As questões foram formuladas com o propósito de favorecer a produção de um contexto de reflexão aprofundada acerca das vivências dessas mães. Para tanto, a técnica de entrevista, uma das modalidades mais utilizadas dentro da pesquisa qualitativa, é uma estratégia de investigação empregada para coleta de dados descritivos na linguagem do próprio entrevistado, permitindo ao entrevistador desenvolver intuitivamente uma idéia sobre o modo como as mães participantes interpretam aspectos de seu mundo circundante (Bogdan \& Biklen, 1997), em particular as vicissitudes ligadas à descoberta da problemática da criança.

\section{Coleta de Dados}

A coleta de dados teve início após a aprovação do projeto pelo Comitê de Ética em Pesquisa da institui- ção (processo CEP FFCLRP-USP n ${ }^{\circ}$ 045/2002) e da autorização formal obtida junto à direção das instituições de atendimento às crianças. Obedeceu-se aos critérios éticos de acordo com os padrões exigidos pela Declaração de Helsink.

Após o levantamento das mães de crianças que freqüentavam as instituições, cada participante foi contatada por telefone pela pesquisadora, que apresentou o convite para participação no estudo. Com a anuência da participante, foi agendada a entrevista.

A aplicação do questionário e da entrevista foi realizada individualmente, em situação face a face, no momento mais oportuno para as participantes. Ocorreu em sala reservada da instituição ou na residência da participante, quando solicitado pela mesma. A pesquisadora procurou manter um ambiente acolhedor e permissivo, encorajando a livre expressão de pensamentos e sentimentos.

Para registro das verbalizações foi utilizado um gravador, mediante anuência prévia das mães. Além do gravador a pesquisadora utilizou a técnica do diário de campo, no qual eram feitas anotações sobre o comportamento das entrevistadas e outras informações que se julgaram importantes para esclarecer o contexto da entrevista.

Para cessar a fase de coleta empregou-se a técnica de saturação dos dados, definida por Fontanella, Ricas e Turato (2008) como a suspensão da inclusão de novos participantes quando os dados obtidos passam a apresentar, na percepção do entrevistador, certa redundância ou recorrência de conteúdos. Desse modo, interrompeuse a captação de novos componentes quando se estabeleceu a convicção de que as informações fornecidas pelas novas participantes pouco acrescentariam ao material já obtido, não contribuindo significativamente para o aperfeiçoamento da reflexão teórica.

\section{Análise dos Dados}

Os dados obtidos com a aplicação do questionário sociodemográfico foram agrupados por meio do cálculo de medidas de tendência central: média e mediana. Para a análise dos dados provenientes da entrevista, adotouse um modelo de transcrição de entrevistas proposto por D. R. D. Araújo (2001), que consiste em uma técnica de editoração de abordagem compreensivista, o que permitiu um tratamento homogêneo e fiel dos relatos. Seguindo a técnica de editoração, as palavras proferidas de forma mais enfática pelas participantes foram sublinhadas. O material audiogravado foi transcrito na íntegra e literalmente, constituindo o corpus de análise.

\section{Análise Concomitante à Coleta de Dados}

As entrevistas foram pré-analisadas no decorrer do processo de coleta, de modo a possibilitar a identificação do momento em que se alcançaria a saturação dos dados. Os relatos foram analisados a partir do método clínicoqualitativo proposto por Turato (2003). 
Posteriormente, empreendeu-se a análise temática (Bardin, 1988; Triviños, 1992), identificando-se os núcleos de sentido contidos nas falas das participantes. $\mathrm{O}$ método utilizado desdobra-se em três etapas: pré-análise, exploração do material e tratamento dos resultados obtidos, inferência e interpretação. Na pré-análise foram realizadas leituras sucessivas do material coletado, que possibilitaram identificar os núcleos de sentido e que constituíram as pré-categorias. Na segunda etapa foram agrupados os segmentos que contemplavam idéias centrais em comum; foram analisados os recortes e estabelecidos os critérios para classificá-los. Segundo Bardin (1988), esta é a fase de organização propriamente dita. Na terceira fase da análise os recortes foram categorizados, isto é, foi feito um agrupamento de conteúdos convergentes e divergentes, o que permitiu comparar as tendências detectadas nos depoimentos e definir o itinerário terapêutico percorrido por mães de crianças com transtorno autístico na busca do diagnóstico e tratamento. Nessa última fase, a pesquisadora retomou as hipóteses e os objetivos iniciais da pesquisa, reformulando-os frente ao material coletado e, por fim, elaborou indicadores que fundamentaram a interpretação final.

Minayo (1994) destaca duas funções na aplicação dessa técnica: a verificação de hipóteses e/ou questões e a descoberta "do que está por trás dos conteúdos manifestos" (p. 74). Na sondagem dos temas emergentes nas entrevistas, buscamos extrair os conteúdos latentes, que pudessem ter relevância na elucidação dos objetivos. A análise buscou aproximar-se da compreensão que as participantes tinham do itinerário terapêutico que percorreram para o estabelecimento do diagnóstico e tratamento.

\section{Resultados e Discussão}

\section{Características Sóciodemográficas}

Das 20 mães incluídas no estudo, 13 (65\%) tinham o filho atendido pela instituição A. Como os dados não diferiram, na análise considerou-se a totalidade das mães. A Tabela 1 indica que a média de idade das participantes cujos filhos freqüentavam as instituições foi de aproximadamente 40 anos, sendo que a participante mais nova tinha 30 anos e a mais velha 54 anos. A idade média das crianças foi de aproximadamente 11 anos nas duas instituições, sendo que a menor tinha três anos e a de maior idade, 14 anos. Em média, as famílias envolvidas no estudo constituíam-se de dois a três filhos, em ambas as instituições, sendo que o mínimo foi de um filho e o máximo de seis filhos.

Tabela 1

Distribuição dos Valores da Média, Desvio-Padrão e Mediana das Características Sociodemográficas das Participantes do Estudo

\begin{tabular}{|c|c|c|c|c|}
\hline Características sociodemográficas & Média $( \pm \mathrm{DP})$ & Mediana & Mínimo & Máximo \\
\hline Idade mãe (anos) & $39,55( \pm 6,84)$ & 41 & 30 & 54 \\
\hline Idade criança (anos) & $10,65( \pm 2,68)$ & 10,5 & 3 & 14 \\
\hline Escolaridade mãe (anos) & $9,85( \pm 4,25)$ & 10,5 & 3 & 15 \\
\hline Renda per capita (salário mínimo) & $1,54( \pm 1,06)$ & 1,38 & 0,42 & 4,58 \\
\hline Número de filhos & $2,65( \pm 1,34)$ & 2,5 & 1 & 6 \\
\hline
\end{tabular}

Com relação à escolaridade das mães, a média foi de aproximadamente 10 anos de estudo. Verificou-se que sete participantes $(35 \%)$ tinham o ensino fundamental (completo ou incompleto), sete $(35 \%)$ o ensino médio (completo ou incompleto) e seis $(30 \%)$ alcançaram o ensino superior (completo ou incompleto). Pela observação dos dados referentes aos anos mínimo e máximo de estudo (Tabela 1), verifica-se que uma participante apresentou apenas três anos de ensino formal, ao passo que outra, no extremo oposto, completou 15 anos de estudo.

Com relação ao estado civil, 18 participantes eram casadas $(90 \%)$, uma declarou estar em união consensual $(5 \%)$ e outra, separada $(5 \%)$. Esse dado indica que apenas uma mãe não tinha a presença do companheiro em casa.

Foi considerado trabalho da mãe quando a participante permanecia pelo menos meio período do dia em outro local que não fosse sua casa. Apenas duas participantes
(10\%) passavam algum dos períodos fora de casa, por motivo de trabalho remunerado. Outras duas participantes $(10 \%)$, uma cursando ensino superior e a outra pósgraduação, relataram passar pelo menos um dos períodos ausente de casa. Apenas duas participantes (10\%) relataram ter auxílio de uma babá para o cuidado com a criança com transtorno autístico.

Contudo, deve ser mencionado que todas as mães que não trabalhavam fora de casa declararam a ocupação com o serviço doméstico juntamente ao cuidado dispensado à criança com transtorno autístico. A maioria das mães trabalhara como doméstica antes da gravidez, dado que revelou uma característica importante dessa população: a maioria das mães, cujas crianças estão nessas instituições, tinha uma baixa condição sócio-econômica.

A análise da variável renda per capita, calculada com base no salário mínimo, mostrou que, em média, cada membro das famílias contava com 1,54 salários mínimos. Observou-se disparidade entre a mínima e máxima 
renda, já que, enquanto que a família de maior poder aquisitivo auferia 4,58 salários por pessoa, outra contava com apenas 0,42 . É importante mencionar que a baixa renda pode limitar as possibilidades de acesso a recursos e serviços de apoio.

Quanto à religiosidade, 11 participantes $(55 \%)$ relataram manter prática regular de cultos religiosos. Outras sete declararam possuir religião, mas não freqüentar cultos $(40 \%)$ e duas relataram não seguir qualquer religião (10\%). Dentre as religiões foram mencionadas: católica, Congregação Cristã do Brasil, "crente"/evangélica e espírita.

Os dados sociodemográficos, como idade da mãe e idade da criança, número de filhos, escolaridade da mãe, religião e renda per capita, indicam que se trata de um grupo heterogêneo, com características diversificadas, à exceção do estado civil (quase todas casadas) e da característica do trabalho da mãe, já que a maioria é cuidadora direta do filho com autismo, ocupando-se também dos afazeres domésticos.

\section{Características da Criança com Autismo}

Com relação aos diagnósticos das crianças, segundo os critérios estabelecidos pelos sistemas de classificação internacional das doenças: oito crianças (40\%) foram diagnosticadas com autismo infantil, uma (5\%) com autismo atípico, seis (30\%) com TID não especificado, com comportamentos autísticos, duas (10\%) com síndrome de Asperger, uma (5\%) com quadro neurológico e comportamentos autísticos e outras três (15\%) com TGD não especificado e comportamentos autísticos.

Em relação à ordem de nascimento, seis crianças com transtorno autístico eram filhos mais velhos (30\%), outros seis eram filhos mais novos $(30 \%)$, sendo uma dessas crianças um dos casos de adoção. Em quatro casos (20\%) as crianças eram filhos únicos, em dois casos essa criança era o segundo filho (10\%) e em um caso era o terceiro filho $(5 \%)$. Houve um caso de gêmeos (crianças adotadas) em que um dos meninos era portador de autismo (5\%).

Apenas duas crianças (10\%) estavam participando do processo de inclusão escolar, ambas na segunda série do ensino fundamental. Nesses casos, freqüentavam a escola em paralelo com as atividades da instituição especializada. Frente a esses dados, constatou-se a dificuldade encontrada para inserção dessas crianças no ambiente escolar, o que coloca em questão a maneira como o processo de inclusão à escola apresenta-se como possibilidade ou não para essas crianças.

Trajetória da Família para Conhecer o Problema da Criança: "Passou por um Monte de Médico"

A história das famílias de crianças com graves prejuízos no desenvolvimento e comportamentos estranhos desde tenra idade foi permeada por uma trajetória de intenso sofrimento emocional, decorrente da incompreensão da própria família acerca dos acontecimentos e da falta de apoio social e dificuldades de acesso a recursos especializados:

As pessoas, ninguém tem noção no Brasil direito do que faz uma pessoa com autismo ... eu mesma me deparei com este fantasma, porque eu não sabia o que era isso ... foi tudo sendo uma caixinha de surpresa na vida da gente (Anita).

Nunca pensei que fosse uma criança com problema... porque ele não nasceu com problema, ele nasceu normal (Cecília).

A falta de compreensão e de informações precisas sobre o quadro colocou a família em uma posição de "não saber" sobre a condição da criança. Em vários casos as mães relataram que identificaram sinais de que o filho não se desenvolvia como as outras crianças e que alertaram os profissionais para esse fato:

Eu conversei com o pediatra, que falou que era assim mesmo, que era normal. Aí, marquei com uma neuro pra ver se ele tinha algum problema de cabeça. Aí fez o exame e falou que ele não tinha nada. Aí eu falei: 'a gente tá achando que ele é autista', ela falou: 'não, autista não é como ele é'. Ela fez uns testes e falou: 'autista ele não é, mas eu vou te passar por uma psiquiatra'. Aí marcou com a psiquiatra (Rachel).

Diante da queixa materna, alguns profissionais interpretavam os sinais relatados pelas mães como evidência de que as crianças eram "mimadas" ou "birrentas":

... ela [médica] falou que o meu filho não tinha era educação, que ele não tinha nada, que aquilo lá era um pouco de... ela quis dizer que ele era mimado, que aquilo era um pouco de falta de corretivo. Aí eu falei: 'tudo bem', mas mesmo assim ela deu haldol pra ele, né? E ela... deu um monte de exames pra fazer (Tarsila).

... falava que era birra de criança, que era porque eu só tinha ele, que era o primeiro filho, era muito mimado. E eu falava: 'não é, a gente não mima, meu marido não é assim, não é desse pai que fica mimando o filho' (Florbela).

Em outros casos, a orientação era de que tais atrasos do desenvolvimento deveriam ser tolerados durante mais um tempo, o que levava os pais a encarar uma árdua espera pela melhora do filho que não ocorria:

Ele [médico] falou que era tudo da minha cabeça e eu fui fazer aquela busca incessante, eu não confiava porque eu nunca achava que todo mundo tava falando a verdade pra mim (Anita).

Com isso, além da desconfiança, um outro sentimento despertado nas mães foi o de ter sua opinião negligenciada:

... eu cansei de especialista, de médico, de psicólogo, de tudo. Falei: 'deixa quieto, vou cuidar do meu filho eu', ainda sem assumir que ele era autista, porque eu, desde o começo, eu sabia que ele tinha características de autista, né? Então, só que eu falava pros especialistas todos. Eu falava assim: 'olha, eu acho que ele é autista' (Sylvia). 
Diante da exacerbação de algum sinal ou sintoma, os pais se mobilizavam, buscando identificar o problema do filho e o tratamento indicado para solucioná-lo. Porém, a família deparou-se com diversas barreiras, como a escassez de recursos humanos e materiais na área da saúde, a desinformação de alguns profissionais da atenção básica e a dificuldade de estabelecimento do diagnóstico correto, especialmente no caso das crianças mais novas.

Nota-se uma decepção profunda em relação aos profissionais consultados, o que permite inferir a importância de oferecer um acolhimento que encoraje a livre expressão de pensamentos e sentimentos maternos, desencadeados tanto pelo convívio doloroso com a situação quanto pelo contato contínuo com serviços que se mostram pouco ou nada resolutivos. Um longo e árduo caminho teve de ser trilhado rumo ao desconhecido, que se caracterizou como um movimento de peregrinação das famílias a hospitais e consultas a diversos profissionais da área de saúde:

... ali naquele hospital eles reviraram, fizeram tudo quanto é exame (Clara).

Mas, você sabe, a gente nunca... tá contente... tá sempre procurando... aí, nessa época, eles ainda não tinham diagnosticado o [nome do filho] como autista. Já achava, mas ninguém falava assim: 'ele é (Anita)

A imprecisão diagnóstica induziu sentimentos de impotência, incrementando a sensação de desesperança e falta de perspectiva:

E continuou o tratamento, sem me dar muita perspectiva daí por diante. Eu senti que ela [psicóloga] também tava perdida (Agatha).

Outros relatos dão conta de que foram estabelecidos diagnósticos equivocados, como deficiência mental e transtornos relacionados, o que só fez aumentar a confusão e o sofrimento materno. O que ajuda a entender porque, por vezes, o diagnóstico correto foi recebido com alívio:

... foi passado pra mim em 15 minutos o que eu procurei em três anos (Djanira).

Via de regra, segundo os relatos maternos, os profissionais não se sensibilizaram com o sofrimento das mães e seu impacto nas relações familiares. Esses desencontros vivenciados na relação com os profissionais despertaram uma gama de sentimentos disfóricos: de desconfiança, raiva, perplexidade e de negligência sistemática com relação às suas opiniões, que dificilmente eram levadas em consideração. Os depoimentos mostram a trajetória sofrida das famílias em busca do diagnóstico e, ao mesmo tempo, um total despreparo dos profissionais para detectar precocemente o transtorno.

Observou-se que a peregrinação se inicia na área médica com o pedido de vários exames neurológicos. Em quatro casos foram detectadas alterações nesses exames. Gradualmente, a trajetória expande-se para outras especialidades, como a Psicologia, Fonoaudiologia e Educação.
As crianças foram diagnosticadas nas idades: uma criança $(5 \%)$ entre 1 e 2 anos de idade, sete crianças (35\%) com 3 anos de idade, seis crianças (30\%) entre 4 e 5 anos e outras seis crianças $(30 \%)$ entre 6 e 7 anos. Diante desses primeiros sinais do transtorno autístico da criança, cinco mães relataram ter vivenciado, inicialmente, sentimentos de revolta, pois não aceitavam a situação. Manifestações de choro e labilidade afetiva, além de sofrimento, tristeza e outros sentimentos, como o de "estar chateada", foram relatados por oito mães. Duas mães se sentiram perdidas e desnorteadas com o diagnóstico do filho. Quatro mães vivenciaram um "impacto", "choque", "baque". Para duas mães, como referido anteriormente, o esclarecimento do diagnóstico trouxe alívio e, para seis mães, não desencadeou qualquer reação por "já saberem" o que a criança tinha ou que ela era "diferente".

A reação de alívio corrobora o estudo de Chamak (2008) naquilo que concerne ao fato de que esclarecer a situação e dar um nome às dificuldades do filho traz uma sensação de conforto aos pais da criança. Contudo, devese levar em consideração a forma pela qual os pais são notificados acerca das condições do filho. Petean (1995) alerta que esse fator pode levar os pais a ter uma percepção errônea do filho, quase sempre negativa.

Posteriormente, as mães relataram a busca das instituições especializadas como forma de enfrentar a situação e procurar assegurar um cuidado especializado para a criança. Logo no início das atividades institucionais, as mães perceberam melhora nos problemas de comportamento do filho, considerando satisfatórias as condições e recursos materiais e humanos encontrados, bem como a infraetrutura do local de atendimento. No entanto, apesar do acolhimento oferecido pelas instituições e da confiança depositada na equipe de profissionais, algumas mães de crianças mais velhas se mostraram desesperançosas com relação às possibilidades de desenvolvimento do filho.

A partir desses relatos abre-se um debate entre, de um lado, o possível despreparo dos profissionais da saúde envolvidos e, do outro, as possíveis resistências maternas à escuta das informações advindas desses mesmos profissionais. No contexto clínico, por exemplo, Martão (2002) apontou que os pais apresentam dificuldades para estabelecer parcerias com o psicoterapeuta. Todavia, Pechberty (2007) discutiu as práticas clínicas atuais a partir do debate entre o cuidado e a educação, relatando que, no tratamento psicoterapêutico da criança, o terapeuta pode estabelecer uma forma de escuta dos pais na qual a função principal não é dar conselhos, mas permitir ao familiar falar "de sua função educativa e das condições inconscientes que aí se atam” (p. 18).

De qualquer forma, a partir de tais resultados, compreende-se que o planejamento de programas, bem como a implementação de serviços especializados, devem priorizar a criação de espaços de escuta e de acompanhamento dos pais, especialmente da mãe, a fim de estabelecer con- 
tatos constantes e facilitar a emergência de uma relação de confiança entre cuidador e profissional. Um atendimento breve pode conseguir lograr, por meio do esclarecimento de aspectos básicos das situações vividas, um fortalecimento da capacidade de adaptação realista por meio da transformação de significações atribuídas pelos pais aos eventos de vida (Fiorini, 1982).

\section{Modos de Lidar com as Dificuldades da Criança: "Saber que Isso é pra Vida Inteira"}

Vencidos os obstáculos do diagnóstico, continuou-se a trajetória permeada por incertezas devido às ofertas escassas de alternativas de tratamento disponíveis. O conhecimento do diagnóstico geralmente foi acompanhado da notícia da cronicidade do transtorno ou da perspectiva de haver avanços limitados do desenvolvimento. Foi preciso tempo para encarar essa realidade de frente: ... eu já fui me conformando, mas eu tinha um pouco de medo de ir atrás... e saber: 'poxa, ele é uma criança doente' (Nise).

... eu pensava que eu ia vir aqui [instituição] e ele ia fazer tratamento e ia sarar e ficar normal. Porque eu não conhecia, eu não tinha contato com criança que tinha problema assim, né? (Djanira).

Nessa última fala destaca-se a força do modelo biomédico e a representação do transtorno autista na perpectiva de uma "doença" a qual se pode tratar, curar e retornar (ou aceder) à normalidade.

Tais vivências sugerem que havia um luto a ser elaborado pela família a partir da definição do diagnóstico. Ao ser instituído, o diagnóstico materializava e, de certo modo, tornava palpável um problema a ser enfrentado. Por outro lado, a superação desse problema impunha um desafio imenso aos familiares. No estudo de Monteiro et al. (2008), mães de crianças com o trantorno autístico manifestaram sentimentos de nulidade, fé e solidão. Muitas vezes deixavam de viver o próprio cotidiano para viverem exclusivamente o do filho.

Alterações de comportamento, manifestações de agressividade e agitação psicomotora, constituíram as principais queixas maternas em relação aos filhos. Segundo os relatos obtidos, a maioria das mães parecia sentir-se, naquele momento da confirmação do diagnóstico, aprisionada em profundo sofrimento. Os sentimentos despertados variaram da surpresa à resignação:

... eu não esperava... um filho assim ninguém espera (Clara).

... a gente tem que estar pronta para muita coisa porque cada época a gente passa por alguns momentos difíceis, né? (Simone).

A maioria das mães afirmou que, uma vez superado o impacto inicial, com o decorrer do tempo a família pareceu ter se habituado à condição da criança, aceitando-a melhor:

... eu falava: 'poxa, agora tem que assumir isso, engolir essa história, assimilar e viver com isso', né? E saber que isso é pra vida inteira, que eu posso melhorar a vida dele, mas que nunca vai ser normal (Sylvia).

Expressões contundentes, como "ter de engolir essa história", "saber que é pra vida inteira" e "nunca vai ser normal" retratam com precisão o drama vivido por essas mães, sugerindo que, por trás de uma aparente resignação, perduram sentimentos de inconformismo, consternação e dúvidas quanto ao futuro do filho. Além disso, os sintomas característicos do transtorno eliciavam desafios constantes:

... a hora que eu tô mais me preocupando, não era antes ... a pior época é essa época de agora, que é umas manias inadequadas que ele tem (Lygia).

Os modos que as mães encontraram para lidar com essas situações desafiadoras envolvem tolerância, paciência, amor e busca de tratamentos diversificados medicamentoso, psicoterapêutico, reeducativo - e suporte institucional.

A convivência diária com a criança com autismo acarretou alteração na dinâmica de funcionamento familiar. A maioria das mães assumiu inteiramente a responsabilidade pelos cuidados à criança, com dedicação integral. Com excessão de duas mães, todas aquelas que, anteriormente, exerciam uma atividade remunerada abandonaram seus empregos. Uma das mães relatou ter trabalhado temporariamente, o que foi sentido por ela como "uma terapia":

... a gente distrai, sabe, conversa... você vê que lá fora, apesar dos meus problemas, tem gente que tem mais, entendeu? E eu gosto porque aí você pode dar um conforto melhor (Hilda).

Este relato permite perceber certa satisfação da participante ao sair do contexto doméstico e poder exercer uma outra função que não a de cuidadora. As adaptações necessárias à convivência com a criança, a adoção de alterações no cotidiano das mães, a revisão de prioridades em suas vidas, enfim, o modo de lidar com as dificuldades da criança, podem potencializar conflitos emocionais e afetivos, que demandam cuidados especiais. Na literatura, algumas estratégias de intervenção preconizadas envolvem tratamentos psicoterapêuticos da criança e seus familiares (C. A. S. Araújo, 2003; Cardoso \& Sielski, 2004; Fonseca, Bussab, \& Simão, 2004; Korbivcher, 2004; Martão, 2002; Pinto, 2004; Ribeiro, 2005; Silveira, 2003), incluindo atendimento ao casal parental, de cunho preventivo (Verdi, 2003) e a intervenção precoce na relação pais-bebê (M. E. L. Silva, 2002).

As mães entrevistas não mencionaram se estavam se beneficiando de suporte terapêutico. No entanto, podese compreender a necessidade de um trabalho no campo da psicologia no que concerne às vivências afetivas dessas famílias, principalmente dos cuidadores diretos de crianças com transtorno autístico. Souza et al. (2004) indicam o trabalho do psicólogo junto à família e aos professores que atendem as crianças, a fim de acompanhar sua evolução e esclarecer o desenvolvimento do 
transtorno, sugerindo que esse atendimento seja oferecido por uma equipe multidisciplinar.

\section{A Sobrecarga Emocional Materna: "Eu Fico Só em Função Dele e da Casa"}

A maioria das mães tomou para si uma diversidade de tarefas e responsabilidades, como o trabalho de casa e o cuidado com o filho. Evidenciou-se claramente a sobrecarga emocional decorrente do cuidado com a criança, acrescentado dos tradicionais afazeres domésticos: cozinhar, lavar, passar, cuidar dos outros filhos, do marido, da limpeza da casa e não apenas da criança com o transtorno autístico.

... a gente sabe o quanto uma mãe é um papel principal na vida de um filho, ainda mais de um filho especial (Lygia).

Eu que tenho que fazer tudo, correr atrás de tudo... fazer feira, ir na farmácia, levar no médico, tudo eu (Frida).

Eu faço tudo, né? Tudo sou eu que tenho que fazer... não sobra nem o sábado, nem o domingo, nem o feriado. Todo dia é a mesma coisa, tem que fazer o serviço doméstico, cuidar do menino, meu marido me ajuda bastante, mas... não tem como falar assim: 'ah, hoje eu não vou fazer isso', sabe? Tem dia que eu tô muito estressada, que eu não tenho vontade de fazer nada. Tenho vontade de sair, de sumir. (Rachel).

... eu cuido do marido e até os filhos, né? Então, tudo me envolve porque ninguém sabe fazer nada, sabe onde tá nada, se eu não tiver perto, vira bagunça (Agatha).

Olha, o que eu faço, acho que outra mãe não fazia. Essa vida, corre pra lá, corre pra cá, é muita coisa pra mim. É roupa, é filho... eu acho que eu dou conta (Virgínia).

Observa-se, por meio dos seguintes relatos, uma interface entre a demanda de cuidados dedicados à criança $\mathrm{e}$ a negligência de cuidados das mães consigo mesmas:

Eu, lógico que eu queria tá assim... com o meu cabelo mais arrumado, sair pra fazê uma... unha. Mas, sabe, eu não tenho... às vezes eu fico em função da casa $\mathrm{e}$ dele. Eu nunca fui também tão vaidosa, mas é claro que você, né, mulher já é o instinto, né, quer andar mais arrumada, quer... mas eu, não. Eu fico muito em função dele e da casa (Tarsila).

Faz parte da vida da gente, a gente não vive sem ele. É o que eu sempre falo: dá trabalho, tudo, mas a gente não sabe ficar sem ele. Se eu, primeiro... se eu viesse na instituição e voltasse em casa para fazer o serviço que às vezes eu não dou conta, aí eu fico lá dentro de casa, eu fico perdida... porque tá fazendo falta, entendeu? Dá trabalho, não é fácil, mas ele também faz falta. A gente não sabe viver sem ele... não vive mais sem ele... quando ele tá aqui [instituição] eu fico em casa cuidando do serviço (Clarice).

Os relatos acima mostram, de maneiras diversas, uma dificuldade das participantes no desempenho de outros papéis sociais que não aquele de cuidadoras. Examinando-se os dados relativos à renda per capita, verifica-se que a situação econômica da maioria das mães não lhes permite ter o auxílio de um ajudante particular, pago pela família, que pudesse auxiliá-las na tarefa de manter o cuidado com a criança. Sendo assim, as crianças mais dependentes contavam apenas com a disponibiliadade materna para manutenção de cuidados. Esse cuidado exclusivo e altamente exigente é demonstrado nos relatos quando as mães utilizam o "eu" para referirem-se às situações de conflito com as crianças:

Ele era uma criança que chorava demais... chorava... aí ele começou a se agredir. Ele se mordia, eu cortava frauda, enfaixava o braço dele, porque ele mordia que ele tirava a frauda. Ele se batia, você não vê que até hoje ele se bate? (Clara).

Nesse contexto, apenas duas mulheres contavam com o auxílio de uma ajudante com quem compartilhavam o cuidado oferecido à criança. Uma delas relatou:

... já faz quase oito anos que eu faço isso. Eu sei que eu não paro não. Se ver, tem coisa pra fazer o dia inteiro, né, e o menino, quando tá lá em casa, eu tô sempre vendo o que ele tá fazendo, tem que ficar de olho nele (Neide).

Observamos certa semelhança com o relato de uma mãe que é a cuidadora em tempo integral do filho:

... eu sou o alimento dele, sou a roupa que ele veste, eu sou tudo... quer dizer... às vezes eu paro pra pensar, eu acho que eu tô errada, que eu tenho que deixar ele caminhar com as pernas dele. Mas eu não consigo, eu não consigo (Simone).

Com ou sem o apoio de uma ajudante, essas mães afirmaram que se sentem totalmente envolvidas, física e emocionalmente, com os cuidados da criança. Porém, parece haver certa liberdade para o desempenho de outros papéis daquelas que contam com essa ajuda de terceiros quando comparadas com as outras:

Eu penso assim, muitas mães saem, né, vai se divertir, né, leva o filho pra ficar, eu não, eu não tenho mais aquela vontade de sair, não tenho mais vontade de sair, me arrumar, eu fico só em função dele e da casa, sabe? (Tarsila).

Mesmo que não se possam conduzir generalizações dos resultados, este estudo mostra que, das 20 mães participantes, apenas duas contavam com o auxílio de uma pessoa paga para ajudar na manutenção dos cuidados com a criança. Essa disponibilidade coincide com o fato de as mesmas trabalharem fora de casa e, portanto, terem melhor condição financeira. Esse fator representou diferença considerável nos relatos maternos quando concerniam à questão do autocuidado e do desempenho de outros papéis socias.

Com relação às principais dificuldades no relacionamento com a criança, foi relatado o controle de esfíncter em oito casos; os comportamentos auto e heteroagressivos foram relatados por oito mães; a criança nervosa, a agitação, o choro e os gritos apareceram nos relatos de 
sete mães como as principais dificuldades; a ecolalia apareceu em um caso como uma dificuldade para lidar; o "fugir" de casa e tirar a roupa foram mencionados por duas mães; e a "falta de obediência" foi relatada em um caso, no qual a gravidade do quadro era menor e a falta de obediência estava relacionada ao contexto escolar. Em outro estudo realizado no contexto brasileiro, Schmidt e Bosa (2007) constataram que os comportamentos do filho que se mostraram mais difíceis para as mães lidarem foram a habilidade de troca de turnos durante conversas e a capacidade para fixar o olhar quando interagia com parceiros.

Desse modo, tendo em vista a incidência de estressores na interação mãe-criança, a situação de conviver com um filho autista solicita vigilância continuada. Como principal cuidadora, recai sobre a mãe o ônus dessa supervisão permanente, o que sem dúvidas contribui para intensificar a sobrecarga. Ao investigarem os níveis de estresse em 30 mães de indivíduos com autismo, Schmidt e Bosa (2007) encontraram que a maior parte das mães (70\%) apresentou altos níveis de estresse.

Os maridos permaneciam fora do lar durante todo o dia. Os relatos divergiram naquilo que se refere ao posicionamento do marido em relação a compartilhar os cuidados dispensados ao filho e fornecer apoio nas tarefas cotidianas. A maioria das mães se queixou de não poder contar com o respaldo do marido nesse sentido:

Ele [marido] mima o menino, que não tem um pingo de medo do pai, não respeita, o pai dele pode falar e ele não tá nem aí ... se eu falo 'não', ele sabe que eu não vou dá mesmo, agora meu marido às vezes fala 'não', mas acaba cedendo (Djanira).

Ah, o meu marido é bem neutro. Ele é uma pessoa muito fechada, ele... ele e o [nome do filho] tem um relacionamento assim, gato e cachorro, tá entendendo? (Tarsila).

E ele me cobra muito! Marido cobra tudo: 'tem que fazer isso, tem que fazer aquilo...' por quê que eu não tô educando direito? Cobra muito! (Florbela).

Segundo os relatos reproduzidos acima, tensões e conflitos conjugais ocorrem decorrentes da confusão das diferentes funções exercidas pelo casal enquanto pai e mãe. No estudo de Shu, Lung e Chan (2000), investigou-se o impacto de crianças autistas sobre a saúde mental de suas mães, concluindo-se que, em alguns casos, as mães relataram que a satisfação matrimonial decaiu com a presença da criança autista e que tais famílias podem precisar de suporte para enfrentar essa crise.

Poucas mães relataram receber apoio por parte do marido:

... o que me ajuda mais é a compreensão do meu marido... é o que me põe pra cima, entendeu? Ele me compreende. Porque não são todos pais que aceitam, você sabe que tem pais que até abandonam, não é verdade? E meu marido compreende tudo (Hilda).

... acho que não existe um pai assim, tão dedicado como ele. Ele é muito bom, ele me ajuda em relação a ele. Às vezes, ele usa mais de psicologia com o [nome do filho] do que eu [riso]. Aí ele fala: 'não é assim, vamos tentar desse jeito, tal'. Aí a gente tenta do jeito que ele tá falando e dá certo. Eu não sei se é porque a gente fica 24 horas com ele e meu marido trabalha o dia inteiro e o tempo que ele tá em casa ele vê as coisas de um outro jeito, vê diferente, percebe as coisas... (Adélia).

Na percepção da maioria das participantes o apoio recebido por parte do marido ou companheiro é insuficiente ou inexistente. Também referem não receber dos demais familiares o apoio de que necessitam:

A minha mãe tem receio de ficar com ele sozinha, a minha irmã fica assim, mas ele obedece bem a minha irmã, sabe? O [marido] fica, mas não ficava. Fica porque a psicóloga falou pra mim: 'você tem que começar a passar ele pra frente, assim... deixar ele com seu marido e sair um pouco sozinha', porque eu mesma acabei fazendo com que só eu podia ajudar ele, cuidar dele (Clarice).

A esperança em relação à situação do filho somente pode ser sustentada pela maioria das mães apoiando-se em crenças religiosas e no pensamento mágico, como o de que foram "escolhidas" para "cuidar dessa criança" predestinada, que lhes fora "designada" por Deus:

... Deus pôs ele assim, porque eu tenho... eu tenho que passar (Tarsila).

Eu sempre pus na minha cabeça que meu filho é o que é porque tinha que ser, porque Deus achou que ele tinha que vim pra mim (Clara).

Se nasceu assim, Deus sabe o porquê. Então a mãe tem que ter amor e pedir pra Deus é... dar sempre condições dela criar ele o melhor possível (Simone).

Os relatos maternos demonstraram que a situação da criança com transtorno autístico exige adaptações não só no cotidiano da mãe, mas no ambiente familiar como um todo, e que alguns pais, mães e irmãos dessas crianças também vivenciam uma sobrecarga psicológica contínua, que compromete sua qualidade de vida, na medida em que afeta o trabalho, o lazer, a saúde física e mental e as finanças. Segundo Fisman e Wolf (1991), os pais de crianças autistas parecem estar particularmente vulneráveis ao estresse gerado pelas dificuldades da criança e a convivência dentro desse clima familiar pode incrementar o risco do desenvolvimento de problemas emocionais e comportamentais nos irmãos.

\section{O Desamparo dos Pais Quanto ao Futuro da Criança: "A Gente Não é Eterno"}

Os relatos maternos expressaram incertezas relacionadas ao futuro da criança com transtorno autístico. As preocupações mencionadas envolveram momentos futuros, particularmente quando as mães já estiverem ausentes ou não puderem mais cuidar dos filhos:

A minha preocupação é com relação ao futuro, a ele ficar sozinho, sem ninguém pra proteger ele, você entendeu? Porque eu protejo ele demais (Simone). 
As mães utilizaram suas narrativas para exprimirem, também, a angústia da família. Dessa maneira, refletindo sobre o planejamento de intervenções para as famílias dessas crianças, salienta-se a importância de o profissional auxiliar os pais e irmãos a reconhecerem a frustração, a raiva e a ambivalência de sentimentos com relação à criança ou referentes à situação vivenciada pela família (Bosa, 2006). A psicoterapia, enquanto método de tratamento para problemas de ordem psicológica, é uma alternativa de eficácia comprovada em certos modelos terapêuticos (Neto \& Féres-Carneiro, 2005).

Algumas mães relataram que se apoiavam na possibilidade de outros filhos ou parentes assumirem no futuro o papel de cuidadores:

... a menina falou pra mim: 'oh mãe, se um dia a senhora chegar a ficar velhinha e chegar...', ela ficou com medo de falar pra mim, né, 'se um dia você ficar velhinha e chegar a faltar, eu tomo conta dele pra senhora', aí quase que eu chorei (Anna).

... eu preparo meus filhos pra cuidarem dele. Eu falo muito: 'quando eu, né... o que eu espero...', porque a gente não é eterno (Simone).

Outras mães, por outro lado, relataram que confiavam na melhora futura do filho, demonstrando sentimentos de fé e esperança apoiados em suas crenças religiosas:

Ah, eu tenho fé em Deus de ver ele melhor. Eu tenho fé em Deus da gente ver ele melhor... porque ele já melhorou muito (Clara).

Às vezes eu penso, mas dá um pouco de medo assim... é... se amanhã ou depois, se ele vai pra uma escola normal e vai continuar vindo aqui [instituição] ou se ele vai... às vezes falam que o autista vai só continuar aqui, que não vai ter uma escola normal pra ele... ah, eu penso que ele adulto, que ele consiga melhorar cada vez mais (Clarice).

No que diz respeito a quem assumiria o cuidado com o filho acometido após a morte dos pais, G. Silva e Santos (2009) também encontraram essa preocupação como uma das maiores fontes de estresse psicológico em mães cuidadoras de filhos com transtorno esquizofrênico.

As crianças que exibiam um comprometimento funcional mais severo e que, portanto, eram mais dependentes de auxílio para desempenharem atividades diárias, ou que apresentavam comportamentos de risco, suscitavam maior preocupação dos pais em relação ao futuro do que as crianças mais independentes.

\section{Considerações Finais}

A análise das entrevistas estimulou reflexões a partir dos núcleos temáticos levantados. A trajetória materna na busca de compreender o problema do filho constituiu um movimento de peregrinação por consultórios, hospitais e profissionais de saúde. Após a busca pelo diagnóstico, as mães depararam-se com a necessidade de elaborar o luto pela criança "perfeita". Ainda que limi- tado às narrativas maternas, o estudo permitiu verificar, por meio dos relatos, que de um modo geral toda a família é afetada pela problemática da criança. O processo de enfrentamento familiar desencadeou mudanças na dinâmica familiar e, em especial, na interação mãefilho. Focalizando essa interação, constatou-se que, diante da situação de vulnerabilidade do filho, as mães passaram a dedicar-se integralmente às crianças, acumulando responsabilidades pelo cuidado com a casa, com a família e com o filho com transtorno autístico, o que acarretou uma sobrecarga física e emocional.

$\mathrm{O}$ presente estudo mostrou que as dificuldades maternas começam nos estágios iniciais do ciclo vital, no momento da busca do diagnóstico. Emergem sentimentos de impotência frente à precariedade dos serviços de saúde, tanto em termos materiais como humanos. O atendimento inadequado acarreta postergação da definição diagnóstica e do estabelecimento do plano terapêutico para o filho, o que exacerba a angústia das mães e impede que sejam oferecidos os cuidados necessários. Quando o diagnóstico é estabelecido e o plano de tratamento instituído, as mães sentem-se reconfortadas. O atendimento realizado pela instituição especializada é avaliado como satisfatório, com profissionais capacitados e recursos materiais adequados às necessidades da criança, o que assegura boa qualidade do cuidado. $\mathrm{O}$ tempo despendido pela criança na escola é aproveitado pelas mães no desempenho de tarefas domésticas, contudo elas reservam pouco para atividades de autocuidado. Mesmo assim, esse tempo em que a instituição se responsabiliza pela produção do cuidado é visto como um alento pelas participantes, sem o quê teriam dificuldade de suportar a sobrecarga física e emocional resultante. Desse modo, o acolhimento das crianças com transtorno autístico, com classificação de risco realizado por profissionais competentes, é visto como um importante instrumento para qualificar o atendimento, contribuindo na divisão de responsabilidades na busca de um cuidado digno e de qualidade aos usuários do serviço.

As mães se vêem ameaçadas nas suas funções de progenitores e frustram-se pela aparente indisposição da criança em aprender. Revelaram um nível elevado de preocupação quanto ao bem-estar de seus filhos no futuro, depois que não puderem mais providenciar cuidados para os mesmos. As mães mais preocupadas tinham crianças com manifestações mais severas, comportamentos mais dependentes em relação aos seus cuidadores e situação socioeconômica desfavorecida. Para Koegel et al. (1992), o nível de prejuízo cognitivo e habilidades de funcionamento independente são focos de preocupações que envolvem o futuro do filho. G. Silva e Santos (2009) encontraram preocupações semelhantes em mães de adultos portadores de esquizofrenia, o que sugere um padrão semelhante, ao menos neste aspecto de desamparo frente ao futuro, em cuidadores familiares de indivíduos com condições crônicas de saúde. 
A literatura psicológica indica a necessidade de oferecer estratégias suportivas para os familiares (Goulart \& Grauben, 2002; Marciano \& Scheuer, 2005). Há um consenso de que os pais encontram-se em condições de elevada vulnerabilidade, dado o desgaste emocional resultante da exposição a condições crônicas de estresse.

Em relação à atenção em saúde mental, é necessário repensar as práticas de cuidado e a organização dos serviços do ponto de vista das necessidades do usuário, aproximando-se da realidade por ele vivenciada quando busca resolver seu problema. A escassez de serviços especializados, com equipe multiprofissional, acarreta o fenômeno da "peregrinação" por sucessivas instituições de saúde e educação, o que prejudica a qualidade do cuidado e a instituição de um plano de intervenção precoce. Aponta-se a necessidade de reorganizar o processo de acolhimento, assim como investir na educação em serviço dos profissionais, de modo a qualificar o atendimento integral às crianças com transtorno autístico e suas famílias.

Verificou-se a complexidade da situação enfrentada pelas mães de crianças com o transtorno autístico. Sugere-se que os serviços especializados ofereçam recursos disponíveis às famílias, principalmente às mães, desde o início do processo diagnóstico. Tais recursos remetem à disponibilidade de equipe multiprofissional. É preciso enfatizar o papel do psicólogo junto às equipes de saúde, no que se refere ao esclarecimento de dúvidas sobre o transtorno autístico, sobre possíveis tratamentos e perspectivas para a criança. Com base nos resultados preconiza-se que a oferta de um espaço de escuta e acolhimento às demandas emergentes possa prevenir eventuais desajustes familiares.

\section{Referências}

Alvarez, A. (1994). Companhia viva (M. A. V. Veronese, Trad.). Porto Alegre, RS: Artes Médicas Sul.

Alvarez, A. (2007). Trouver la bonne longueur d'ondes: les outils de communication avec les enfants autistes. In F. Touati, F. Joly \& M.-C. Laznik (Eds.), Langage, voix et parole dans l'autisme (pp. 239-260). Paris: Presses Universitaires de France.

American Psychiatric Association. (2002). DSM IV-TR: Diagnostic and statistical manual of mental disorders, text revised ( $4^{\text {nd }}$ ed.). Washington, DC: Author.

Araújo, D. R. D. (2001). Como transcrever sua entrevista: Técnica de editoração da transcrição de entrevista em pesquisa de abordagem compreensiva. Psico, 32(1), 147-157.

Araújo, C. A. S. (2003). O autismo na teoria do amadurecimento de Winnicott. Natureza Humana, 5(1), 39-58.

Bardin, L. (1988). Análise de conteúdo (L. Antero Neto \& A. Pinheiro, Trads.). Lisboa, Portugal: Edições 70.

Bogdan, R., \& Biklen, S. (1997). Investigação qualitativa em Educação. Porto. Portugal: Porto.

Bolton, P., MacDonald, H., Pickles, A., Rios, P., Goode, S., Crowson, M., et al. (1994). A case-control family history study of autism. Journal of Child Psychology and Psychiatry and Allied Disciplines, 35(5), 877-900.
Bolton, P. F., Pickles, A., Murphy, M., \& Rutter, M. (1998). Autism, affective and other psychiatric disorders: Patterns of familial aggregation. Psychological Medicine, 28(2), 385-395.

Bosa, C. A. (2006). Autismo: Intervenções psicoeducacionais. Revista Brasileira de Psiquiatria, 28(1), 47-53.

Bosa, C. A., \& Callias, M. (2000). Autismo: Breve revisão de diferentes abordagens. Psicologia: Reflexão e Crítica, 13(1), 167-177.

Cardoso, C. G., \& Sielski, M. (2004). Sobre o autismo: O real, a repetição e a transferência. Psicologia Argumento, 22(37), 39-44.

Carr, D. (2003). Effects of exemplar training in exclusion responding on auditory-visual discrimination tasks with children with autism. Journal of Applied Behavior Analysis, 36(4), 507-524.

Cavalcanti, A. E., \& Rocha, P. S. (2002). Autismo: Clínica psicanalítica. São Paulo, SP: Casa do Psicólogo.

Chamak, B. (2008). Autism and social movements: French parents' associations and international autistic individuals' organizations. Sociology of Health \& Illness, 30(1), 76-96.

Cloutier, P. F., Manion, I. G., Walker, J. G., \& Johnson, S. M. (2002). Emotionally focused interventions couples with chronically ill children: A 2-year follow-up. Journal of Marital and Family Therapy, 28(4), 391-398.

Ducharme, J. M., \& Drain, T. L. (2004). Errorless academic compliance training: Improving generalized cooperation with parental requests in children with autism. Journal of the American Academy of Child \& Adolescent Psychiatry, 43(2), 163-171.

El-Ghoroury, N. H., \& Romanczyk, R. G. (1999). Play interactions of family members towards children with autism. Journal of Autism and Developmental Disorders, 29(3), 249258.

Fávero, M. A. B. (2005). Trajetória e sobrecarga emocional da família de crianças autistas: Relatos maternos. Dissertação de Mestrado não-publicada, Faculdade de Filosofia, Ciências e Letras, Universidade de São Paulo, Ribeirão Preto, SP.

Fávero, M. A. B., \& Santos, M. A. (2005). Autismo infantil e estresse familiar: Uma revisão sistemática da literatura. Psicologia: Reflexão e Crítica, 18(3), 358-369.

Fiorini, H. J. (1982). Psicoterapia dinâmica breve: Contribuições para uma teoria da técnica. In H. J. Fiorini, Teoria $e$ técnica de psicoterapias (pp. 21-45). Rio de Janeiro, RJ: Francisco Alves.

Fisman, S., \& Wolf, L. (1991). The handicapped child: Psychological effects of parental, marital, and sibling relationships. Psychological Clinics of North America, 14(1), 199-217.

Fonseca, V. R. J. R. M., Bussab, V. S. R., \& Simão, L. M. (2004). Transtornos autísticos e espaço dialógico: Breve conversa entre a Psicanálise e o Dialogismo. Revista Brasileira de Psicanálise, 38(3), 679-692.

Fontanella, B. J. B., Ricas, J., \& Turato, E. R. (2008). Amostragem por saturação em pesquisas qualitativas em saúde: Contribuições teóricas. Cadernos de Saúde Pública, 24(1), 2008, 17-27.

Francis, K. (2005). Autism interventions: A critical update. Developmental Medicine \& Child Neurology, 47(7), 493499.

Gerhardt, T. E. (2006). Itinerários terapêuticos em situação de pobreza: Diversidade e pluralidade. Cadernos de Saúde Pública, 22(11), 2449-2463. 
Goulart, P., \& Grauben, J. A. (2002). Estudos sobre autismo em análise do comportamento: Aspectos metodológicos. Revista Brasileira de Terapia Comportamental Cognitiva, 4(2), 151-165.

Hare, D. J., Pratt, C, Burton, M., Bromley, J., \& Emerson, E. (2004). The health and social care needs of family carers supporting adults with autistic spectrum disorders. Autism, $8(4), 425-444$.

Henderson, D., \& Vandenberg, B. (1992). Factors influencing adjustment in the families of autistic children. Psychological Reports, 71(1), 167-171.

Klin, A. (2006). Autismo e síndrome de Aspeger: Uma visão geral. Revista Brasileira Psiquiatria, 28(1), 3-11.

Koegel, R. L., Schreibman, L., Loos, L. M., Dirlich-Wilhelm, H., Dunlap, G., Robbins, F. R., et al. (1992). Consistent stress profiles in mothers of children with autism. Journal of Autism and Developmental Disorders, 22(2), 205-216.

Korbivcher, C. F. (2004). La teoria de las transformaciones y los estados autistas. Transformaciones autísticas: una propuesta. Revista Chilena de Psicoanálisis, 21(2), 221233.

Kovács, M. J. (1997). Deficiência adquirida e qualidade de vida: Possibilidades de intervenção psicológica. In E. A. F. S. Masini, E. Becker, E. B. Pinto, L. A. Amaral, M. J. Kovács, \& M. L. T. M. Amiralian (Eds.), Deficiência: Alternativas de intervenção (pp. 95-125). São Paulo, SP: Casa do Psicólogo.

Kupfer, M. C. M. (1997). Modelos de atendimento à criança psicótica. Boletim de Psicologia, 48(109), 77-96.

Kupfer, M. C. M., Rocha, P. S., Cavalcanti, A. E., Escobar, A. M. U., \& Fingerman, D. (2008). Apresentação e debate em torno da Pesquisa Multicêntrica de Indicadores Clínicos de Risco para o Desenvolvimento Infantil. In R. Lerner \& M. C. M. Kupfer (Eds.), Psicanálise com crianças: Clínica e pesquisa (pp. 49-62). São Paulo, SP: Escuta.

Lampreia, C. (2003). Avaliações quantitativa e qualitativa de um menino autista: Uma análise crítica. Psicologia em Estudo (Maringá), 8(1), 57-65.

Lerner, R. (2008). Apresentação. In R. Lerner \& M. C. M. Kupfer (Eds.), Psicanálise com crianças: Clínica e pesqui$s a$ (pp. 5-14). São Paulo, SP: Escuta.

Lino Silva, M. E. (1998). Gente estranha: Um olhar psicanalítico para o autista. Estudos de Psicologia (Campinas), 15(2), 59-67.

Marciano, A. R. F., \& Scheuer, C. I. (2005). Quality of life in siblings of autistic patients. Revista Brasileira de Psiquiatria, 27(1), 67-69.

Martão, M. I. S. (2002). Filhos autistas e seus pais: Um estudo compreensivo. Dissertação de Mestrado não-publicada, Instituto de Psicologia, Universidade de São Paulo, SP.

Mickelson, K. D., Wroble, M., \& Helgeson, V. S. (1999). 'Why my child?': Parental attributions for children's special needs. Journal of Applied Social Psychology, 29(6), 1263-1292.

Minayo, M. C. S. (1994). O desafio do conhecimento: Pesquisa qualitativa em saúde. São Paulo, SP: Hucitec.

Moes, D., Koegel, R. L., Schreibman, L., \& Loos, L. M. (1992). Stress profiles for mothers and fathers of children with autism. Psychological Reports, 71(3), 1272-1274.

Monteiro, C. F. S., Batista, D. O. N. M., Moraes, E. G. C., Magalhães, T. S., Nunes, B. M. V. T., \& Moura, M. E. B. (2008). Vivências maternas na realidade de ter um filho autista: Uma compreensão pela enfermagem. Revista Brasileira de Enfermagem, 61(3), 330-335.
Morales, E., Martinez, R., \& Váldes, A. (1995). Um modelo de acción com um miembro autista. Revista de Psiquiatria (Chile), 12(1), 26-33.

Neto, O. D., \& Féres-Carneiro, T. (2005). Eficácia psicoterapêutica: Terapia de família e o efeito "Dodô". Estudos de Psicologia (Natal), 10(3), 355-361.

Organização Mundial da Saúde (2000). CID-10, Classificação de transtornos mentais e de comportamento: Descrições clínicas e diretrizes diagnósticas (Centro Colaborador da Organização Mundial da Saúde para Classificação de Doenças em Português, Trad.). Porto Alegre, RS: Artes Médicas.

Pechberty, B. (2007). O debate entre o cuidado e a educação: Práticas clínicas atuais. Estilos da Clínica, 12(22), 14-25.

Petean, E. B. L. (1995). Avaliação qualitativa dos aspectos psicológicos do aconselhamento genético através do estudo prospectivo do atendimento das famílias. Tese de Doutorado não-publicada, Universidade de Campinas, SP.

Pinto, E. B. (2004). Autismo, deficiência intelectual e distúrbios relacionados: Para uma compreensão mútua. Mudanças, 12(1), 193-203.

Piven, J., \& Palmer, P. (1999). Psychiatric disorder and the broad autism phenotype: Evidence from a family study of multiple-incidence autism families. American Journal of Psychiatry, 56(4), 557-563.

Prado, M. C. C. (1999). Entrando em contato com o mundo da família autista: Em busca de meios de comunicação. Informe Psiquiátrico, 18(1), 3-13.

Ramachardan, V. S., \& Oberman, L. M. (2006). Espelhos quebrados: Uma teoria sobre o autismo. Scientific American (Brasil), 55, 53-59.

Reinaldo, A. M. S. (2003). O itinerário terapêutico em saúde mental pela história oral de vida de um paciente psiquiátrico. Tese de Doutorado não-publicada, Escola de Enfermagem, Universidade de São Paulo, Ribeirão Preto, SP.

Ribeiro, P. M. M. (2005). Tecendo o continente: Pensamento como superfície sensorial. Revista Brasileira de Psicanálise, 39(4), 169-182.

Sanders, J. L., \& Morgan, S. B. (1997). Family stress and adjustment as perceived by parents of children with autism or Down syndrome: Implications for intervention. Child and Family Behavior Therapy, 19(4), 15-32.

Schmidt, C., \& Bosa, C. (2003). A investigação do impacto do autismo na família: Revisão crítica da literatura e proposta de um novo modelo. Interação em Psicologia, 7(2), 111-120.

Schmidt, C., \& Bosa, C. (2007). Estresse e auto-eficácia em mães de pessoas com autismo. Arquivos Brasileiros de Psicologia, 59(2), 179-191.

Shu, B. C., Lung, F. W., \& Chan, Y. Y. (2000). The mental helth in mothers with autistic children: A case-control study in southern Taiwan. Kaohsiung Journal Medicine Science, 16, 308-314.

Siklos, S., \& Kerns, K. A. (2006). Assessing need for social support in parents of children with autism and Down syndrome. Journal of Autism and Developmental Disorders, 36(7), 921-933.

Silva, G., \& Santos, M. A. (2009). Esquizofrenia: Dando voz à mãe cuidadora. Estudos de Psicologia (Campinas).

Silva, M. E. L. (2002). Um self sem berço: Relato de uma intervenção precoce na relação pais-bebê. Revista Brasileira de Psicanálise, 36(3), 541-565.

Silveira, T. C. (2003). A Psicanálise e os impasses da constituição subjetiva. Psyche (São Paulo), 7(11), 117-132. 
Smith, V. K., \& Dillenbeck, A. (2006). Developing and implementing early intervention plans for children with autism spectrum disorders. Seminars in Speech Language, 27(1), 10-20.

Souza, J. C., Fraga, L. L., Oliveira, M. R., Buchara, M. S., Straliotto, N. C., Rosário, S. P., et al. (2004). Atuação do psicólogo frente aos transtornos globais do desenvolvimento infantil. Psicologia: Ciência e Profissão, 24(2), 24-31.

Sprovieri, M. H. S., \& Assumpção, F. B., Jr. (2001). Dinâmica familiar de crianças autistas. Arquivos de Neuropsiquiatria, 79(2), 230-237.

Talbot, A., Hales, R. E., \& Yudofsky, S. C. (1992). Tratado de Psiquiatria. Porto Alegre, RS: Artes Médicas.

Teperman, D. W. (1999). Do desejo dos pais ao sujeito do desejo. Estilos da Clínica, 4(7), 151-158.

Triviños, A. N. S. (1992). Introdução à pesquisa em Ciências Sociais: A pesquisa qualitativa em Educação. São Paulo, SP: Atlas.

Turato, E. R. (2003). Tratado de metodologia da pesquisa clínico-qualitativa: Construção teórico-epistemológica, discussão comparada e aplicação nas áreas de saúde e humanas. Petrópolis, RJ: Vozes.

Verdi, M. T. (2003). Grupo de pais de crianças autistas: Tessitura dos vínculos. Revista da SPAGESP, 4(4), 110-114.

Vitiello, B., Aman, M. G., Scahill, L., McCracken, J. T., McDougle, C. J., Tierney, E., et al. (2005). Research knowledge among parents of children participating in a randomized clinical trial. Journal of the American Academy of Child \& Adolescent Psychiatry, 44(2), 145-149.

Wallace, C., Leask, J., \& Trevena, L. J. (2006). Effects of a web based decision aid on parental attitudes to MMR vaccination: A before and after study. British Medical Journal, 21(332), 146-149.

Williams, E. (2003). A comparative review of early forms of object-directed play and parent-infant play in typical infants and young children with autism. Autism, 7(4), 361-377.

Williams, K. R., \& Wishart, J. G. (2003). The Son-Rise Program intervention for autism: An investigation into family experiences. Journal of Intellectual Disability Research, 47(4/ 5), 291-299.

Young, R. L., Brewer, N., \& Pattison, C. (2003). Parental identification of early behavioral abnormalities in children with autistic disorder. Autism, 7(2), 125-143.

Zilbovicius, M., Meresse, I., \& Boddaert, N. (2006). Autismo: Neuroimagem. Revista Brasileira de Psiquiatria, 28(1), 2128.

Zukauskas, P. R., \& Assumpção, F. B. (2002). Avaliação qualitativa da noção de tempo em um quadro de autismo de alto funcionamento. Infanto: Revista de Neuropsiquiatria da Infância e Adolescência, 10(2), 90-95. 